\title{
A Systematic Review on Business Analytics
}

\author{
Jiarui Yin (iD, Vicenc Fernandez (iD) \\ TechTalent-Lab, Department of Management, Universitat Politècnica de Catalunya $\cdot$ BarcelonaTech (Spain) \\ yin_jiarui@qq.com, vicenc.fernandez@upc.edu
}

Received: October 2019

Accepted: February 2020

\begin{abstract}
:
Purpose: Business analytics, a buzzword of the recent decade, has been applied by thousands of enterprises to help generate more values and enhance their business performance. However, many aspects of business analytics remain unclear. This study explores different perspectives on the definition of business analytics and its relation with business intelligence Moreover, we illustrate the applications of business analytics in both business areas and industry sectors and shed light on the education in business analytics. Ultimately, to facilitate future research, we summarize several research techniques used in the literature reviewed.
\end{abstract}

Design/methodology/approach: We set well-established selection criteria to select relevant literature from two widely recognized databases: Web of Science and Scopus. Based on the bibliometric information of the papers selected, we did a bibliometric analysis. Afterward, we reviewed the literature and coded relevant sections in an inductive way using MAXQDA. Then we compared and synthesized the coded information.

Findings: There are mainly four findings. Firstly, according to the bibliometric analysis, literature about business analytics is growing exponentially. Secondly, business analytics is a system enabled by machine learning techniques aiming at promoting the efficiency and performance of an organization by supporting the decision-making process. Thirdly, the application of business analytics is comprehensive, not only in specific areas of a company but also in different industry sectors. Finally, business analytics is interdisciplinary, and the successful training should involve technical, analytical, and business skills.

Originality/value: This systematic review, as a synthesis of the current research on business analytics, can serve as a quick guide for new researchers and practitioners in the field, while experienced scholars can also benefit from this work, taking it as a practical reference.

Keywords: business analytics, analytics, decision support, systematic review, business intelligence

\section{To cite this article:}

Yin, J., \& Fernandez, V. (2020). A systematic review on business analytics. Journal of Industrial Engineering and Management, 13(2), 283-295. https://doi.org/10.3926/jiem.3030 


\section{Introduction}

In recent decades, data are reshaping our perspective towards the world at a fast pace (Hsinchun, Roger \& Veda, 2012). A bunch of buzzwords such as Internet of things, artificial intelligence, and machine learning is getting popular in the setting of big data, and business analytics is one among them. According to the popularity curve in Google Trends, business analytics is getting more attention at a steady pace in the recent 10 years worldwide.

Despite the popularity, seeing from the number of papers related to business analytics in the databases, the research in business analytics is not abundant. There is a lack of studies that systematically summarize the existing research on various facets of business analytics. In order to clarify the current knowledge about business analytics, we propose three main research questions: What are the different approaches to define business analytics? What are the applications of business analytics? What are the typical research techniques in the field? To answer the questions, we conducted a systematic review with literature obtained from two widely recognized databases: Web of Science and Scopus (Harzing \& Alakangas, 2016).

After the introduction, we present the methodology of this study and the process of analysis. What follows is a bibliometric analysis to have an overview of the field, specifically, the trend, the top journals, top authors, and the countries in which the authors did their research. The following section dedicates to the exploration of different perspectives on the definition of business analytics, its functionality, and the difference and relation between business analytics and business intelligence. Afterward, there is a section discussing the applications of business analytics, particularly, business areas and industry sectors. Then we summarize the situation of education and training in business analytics. After that, we recap the research techniques discovered. Finally, the last section concludes the study.

\section{Methodology}

There are many misunderstandings and unclear aspects of business analytics due to the novelty of this emerging field. In order to clarify these aspects and answer our research questions, we carried out a systematic review, which allows us to identify, evaluate, and synthesize the existing knowledge of this topic from researchers and practitioners in the filed in a systematic and reproducible way (Fink, 2005). Apart from reviewing the literature, we took the bibliometric information of the papers to conduct a bibliometric analysis. We categorized and grouped the papers based on the year of publication, the source of the paper, the authors, the places where the authors did their research.

\subsection{Information Source and Criteria of Selection}

We obtained academic literature from two databases: Web of Science and Scopus. These two databases are widely recognized and contain publications of high quality from peer-reviewed journals (Harzing \& Alakangas, 2016). As a set of well-established selection criteria are the foundation of a rigorous systematic review, we set several rules for literature selection before screening publications in the database (Okoli, 2015). Firstly, the publications should contain business analytics in the title. Secondly, we only considered publications in English. Thirdly, regarding the publication type, we included articles and reviews. Furthermore, to include papers of high impact, we set a requirement on number of citations. For those papers published before 2017, we only considered those been cited more than five times, and for the papers published in 2017 and 2018, which usually have fewer citations due to the newness, we considered papers been cited at least once. By setting this threshold of citation number, we included the papers of high impact in the academia in this study. Finally, the core of the selection process, to ensure the relevance of the publications selected, searching business analytics in titles is not enough. And it is not feasible to read all the papers entirely even though the first four criteria would have narrowed the number of results. To deal with this, we read the abstracts to decide if the paper fits with the goal of the research. Additionally, the length of the paper should be long enough to cover adequate information, and the content of the paper should be relevant to business analytics.

\subsection{Process of Selection}

Figure 1 is a flowchart presenting the selection process. In July 2018, we searched in Web of Science with the search word business analytics in titles. The number of results was 317. After filtered the language (English) and type of 
the document (article and review), we had 138 results. We did the same in Scopus. We searched business analytics in titles. The result number was 474 . After filtered the language and the type of the document, we had a result of 160 papers. Then we applied the selection criteria of citation times, for the papers before 2017, more than five citations, and papers published between 2017 and 2018, at least one citation. The next step was to read the abstracts to decide if a paper was relevant to the research. After the whole process, we had 46 papers ready for further reading. Later, we excluded six papers that were limited in length or of low relevance to business analytics in the content. Finally, the number was reduced to 40.

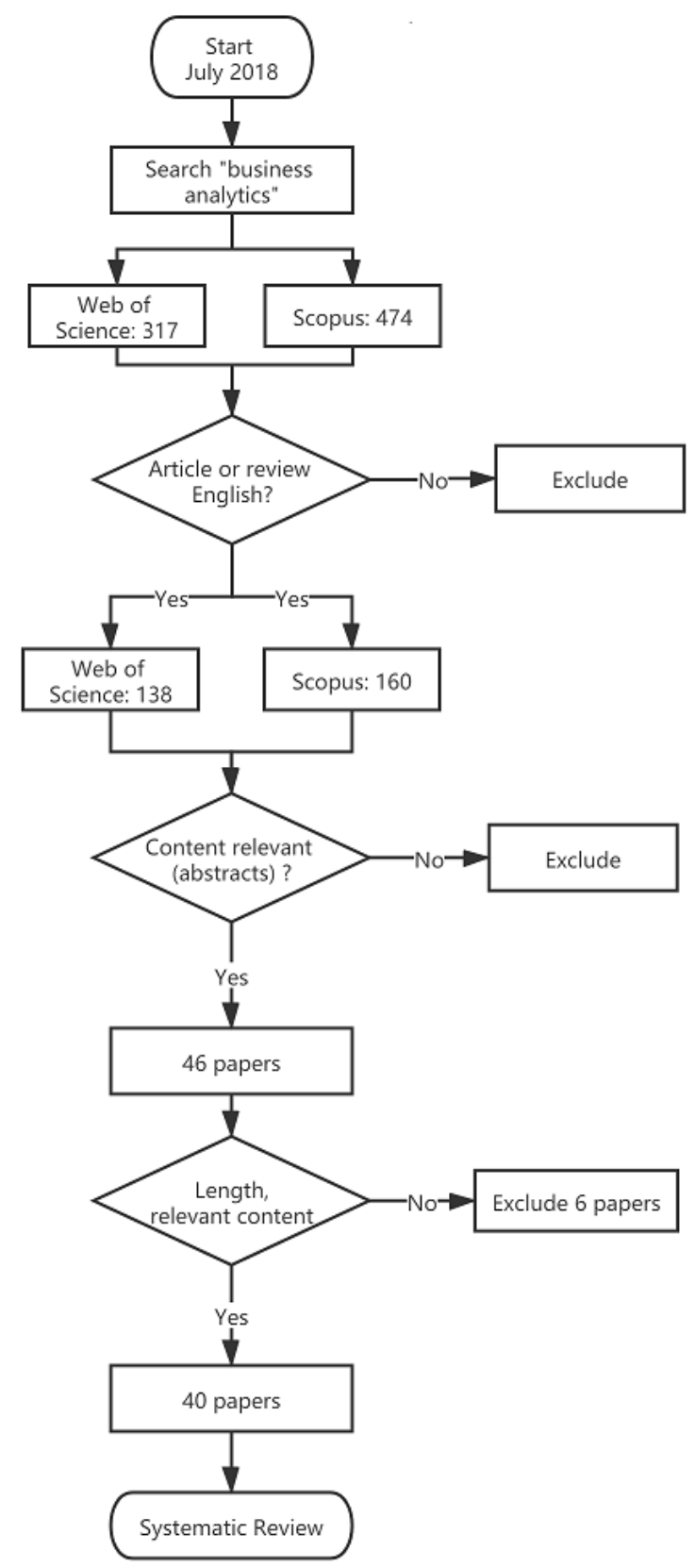

Figure 1. Process of Selection

\subsection{Process of Analysis}

In order to analyze the papers, we carefully reviewed the literature. During the reading, we highlighted the important parts and coded them. We did coding in an inductive way, which means we highlighted the sections related to our research questions and categorized them into codes along the reading process. For example, there are 
definition, business areas, industry sectors, education and training. We used MAXQDA, a popular tool of qualitative text analysis, to facilitate the process. Comparing the coded sections among the papers, we can evaluate and summarize different aspects of business analytics.

\section{Bibliometric Analysis}

As the ledged indicates, the dotted line and the dashed line in figure 2 show the result in a time frame respectively, and the solid line stands for the allocation of the 40 papers finally selected in different years.

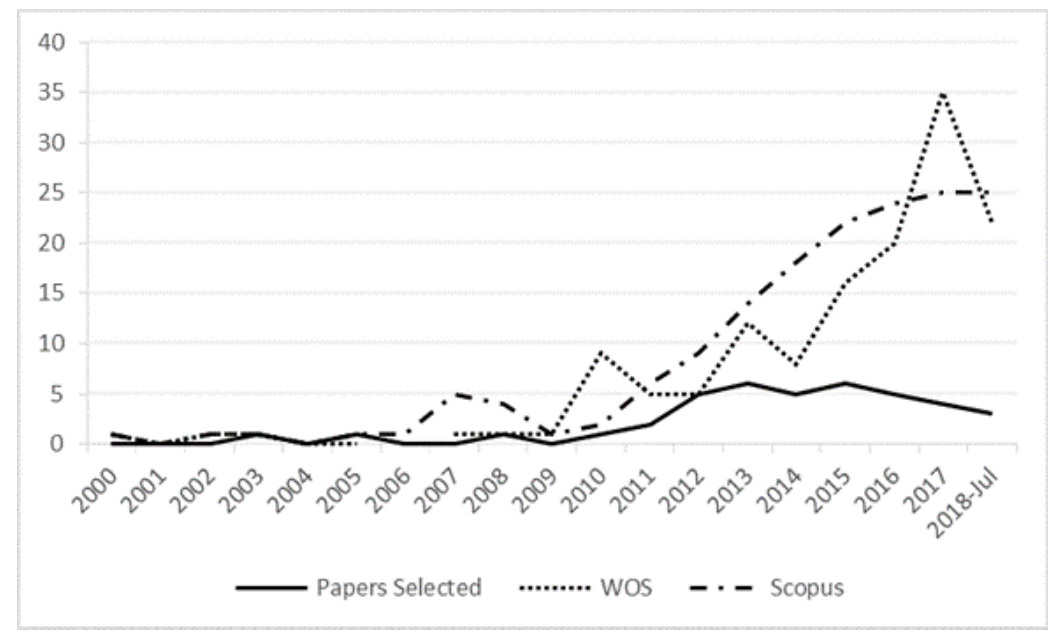

Figure 2. Distribution of the papers selected

As the solid line indicates, there is an increase in the number of papers from 2010 and a decrease from 2015. Nevertheless, this does not imply that the number of papers published about business analytics is declining between the years. The fall is the consequence of our selection criteria, that we consider the papers published before 2017 with citation times more than five, and papers more recently published reasonably have fewer citation times. To see a more general trend of papers published about business analytics, we can focus on the dotted line and dash line: the year 2009 has witnessed a boost of the term business analytics, and the popularity continues to the present. Notice that the figure only represents the trend until July 2018; thus, we can reasonably speculate that by the end of 2018 , the tail of the lines will be around twice higher than the current volume.

Among the 40 papers, the most frequent source is Decision Support Systems (four times). The following seven journals appeared twice: ACM Transactions on Management Information Systems, European Journal of Operational Research, Expert Systems with Applications, International Journal of Information Management, International Journal of Productivity and Performance Management, Journal of Computer Information Systems, Omega (United Kingdom). The rest of the journals appeared once.

There are 113 authors identified in total in the selected literature, and 10 of them appeared more than once in the papers. Individually, Kevin McCormack ranks the first with appearance in three papers. The other nine authors appeared twice, namely, Bongsug Chae, Hsinchun Chen, Roger H. L. Chiang, Lakshmi S. Iyer, Klaus Moeller, Marcos Paulo Oliveira, Marten Schlaefke, Graeme Shanks, Peter Trkman. This list includes the two authors of the most cited paper (Business intelligence and analytics: From big data to big impact): Hsinchun Chen and Roger H. L. Chiang.

Taking into account the place in which the authors did their research, there are 16 countries identified in total, located in five continents. Regarding the continents, North America holds the first position, in which 54 authors conducted their research. Followed by Europe, 30 researchers did their work on this continent. Respecting the countries, the top three were the US, Australia, and the UK, appeared 51,12, and nine times, respectively. Brazil located in fourth place with eight times of appearance. Both Germany and Greece showed seven times in the list and shared the fifth position. 


\section{Definition, Functionality, and Difference}

During the process of examining the literature, we found that there was an absence of common understanding of the term business analytics. In this section, we synthesize different perspectives of the definition. Additionally, we discuss the functionality of business analytics since it is important to understand the definition. Finally, we discuss the relation and difference between the two popular terms in the literature: business analytics and business intelligence.

\subsection{Definition of Business Analytics}

Business analytics is about getting useful information from business data to promote the efficiency of an enterprise and generate more business values (Shen \& Tzeng, 2016), and the target of business analytics is to get insight from data and support making fact-based decisions (Davenport \& Harris, 2007). More specifically, business analytics can be viewed as "a broad umbrella entailing many problems and solutions, such as demand forecasting and conditioning, resource capacity planning, workforce planning, salesforce modeling and optimization, revenue forecasting, customer/product analytics, and enterprise recommender systems" (Varshney \& Mojsilovic, 2011: page 83). From the perspective of disciplines, business analytics is a branch of management science, which can be seen as an application of operation research, and a combination of knowledge of signal processing, computer science, and statistics (Varshney \& Mojsilovic, 2011).

Institute for Operations Research and Management Science (INFROMS) define business analytics that "it facilitates the realization of business objectives through reporting of data to analyze trends, creating predictive models for forecasting, and optimizing business processes for enhanced performance" (Chiang, Goes \& Stohr, 2012: page 12:2). Business analytics is identified into three levels: descriptive, predictive, and prescriptive. Descriptive analytics underlines in recognizing the trends and causes of what is going on in the business; predictive analytics focuses on using statistical methods such as machine learning to discover what is possible to happen in the future; prescriptive analytics, constitutes of providing advice for making decisions based on the information acquired in the first two processes (Sharda, Asamoah \& Ponna, 2013). To summarize, descriptive analytics aims at understanding what happened in the past and what is happening at present. Predictive analytics focuses on forecasting the future situation based on the information on hand. Prescriptive analytics goes beyond the first two kinds of analytics and targets at participating in the decision-making process by providing useful and actionable suggestions for business problems. The implementation of descriptive, predictive, and prescriptive analytics can help companies make smarter decisions and generate more business value (Hindle \& Vidgen, 2018).

Analytics, the short form of business analytics in a business context (Gorman \& Klimberg, 2014; Holsapple, Lee-Post \& Pakath, 2014), can be considered as data analytics in business domain (Duan \& Xiong, 2015; Shen \& Tzeng, 2016). Furthermore, business analytics can also be viewed as the employment of big data analytics in business (Shen \& Tzeng, 2016) since the data that business analytics processes can be big and unstructured (Hindle \& Vidgen, 2018). Also, business analytics is enabled by techniques and methods such as data mining, data warehousing, statistical modeling, quantitative analysis, visualization, and other information technologies (Davenport \& Harris, 2007; Shen \& Tzeng, 2016). To link another popular term, data science, Hsinchun et al. (2012) view business analytics as the application of data science in business fields.

\subsection{Functionality of Business Analytics}

Business analytics has four main functions. First and foremost, business analytics helps enterprises to objectify the decision-making process rather than making decisions based on pure experience and assumptions (Schläfke, Silvi \& Möller, 2013; Troilo, Bouchet, Urban \& Sutton, 2016). Secondly, business analytics can accelerate the decision-making process (Hindle \& Vidgen, 2018; Sharma, Mithas \& Kankanhalli, 2014). Thirdly, using business analytics can have a better understanding of customers and markets so that enterprises can improve customer services and the quality of customer marketing (Schläfke et al., 2013; Troilo et al., 2016). Finally, apart from helping inside by supporting decision-making process, business analytics also helps understand the external environment such as customers and other principal stakeholders (Calof, Richards \& Smith, 2015). 
The implementation of business analytics is all about fully taking advantage of (internal and external) data to increase operation efficiency and business performance (Chae \& Olson, 2013; Oliveira, McCormack \& Trkman, 2012), and this kind of improvement is the result of effective decision making enabled by business analytics (Larson \& Chang, 2016). Furthermore, the improvement is enabled by three kinds of business analytics. Descriptive analytics helps enterprises to be fully informed of the historical and present situations (Appelbaum, Kogan, Vasarhelyi \& Yan, 2017). Predictive analytics supports companies to anticipate the future, for example, the possible influence by the changes in policies or potential actions may be taken by competitors (Appelbaum et al., 2017; Schläfke et al., 2013). Prescriptive analytics participates in the decision-making process by providing solid and fact-based recommendations empowered by advanced machine learning techniques (Appelbaum et al., 2017). Business insights and understandings are generated in all these three types of analytics. Additionally, business analytics can be applied not only to the core business to promote business revenue (Hindle \& Vidgen, 2018) but also to functional departments inside enterprises, for example, supply chain [e.g. (Oliveira et al., 2012)], human resources [e.g. (Pape, 2016)], and finance [e.g. (Appelbaum et al., 2017)].

\subsection{Relation and Difference between Business Analytics and Business Intelligence}

Business analytics and business intelligence are two frequently used terms. However, the relations and differences between the two are not well-understood, and opinions towards business analytics and business intelligence vary. Chae and Olson (2013) consider business analytics and business intelligence as similar terms, both reflect the use of analytical capabilities for decision support, whereas Wixom, Yen, and Relich (2013) view business analytics as a process and business intelligence as insights and business intelligence is obtained from business analytics. Gorman and Klimberg (2014) think business analytics as an extension of business intelligence by incorporating advanced statistical and operation research techniques. Varshney and Mojsilovic (2011: page 84) share the same idea that "from the managerial perspective, business analytics is an outgrowth of what is known as business intelligence".

Business analytics is categorized into three levels (descriptive, predictive, and prescriptive), which reflect the different domains and utilities of business analytics. These levels also clarify the difference between business analytics and business intelligence. Sharda et al. (2013) suggest that business intelligence heavily relies on descriptive analytics, and the representative technology of business intelligence is data visualization. Varshney and Mojsilovic (2011) agree on the opinion above that even though business intelligence is useful in reporting data, but the ability of business intelligence systems is limited due to the absence of predictive modeling and recommendations produced by algorithms for decision-making.

Chae (2014) state the transformation that business intelligence rose up in the 19th century with the functionality to provide charts and graphs to managers. The authors mention that in today's complex and competitive business environment, business analytics is more popular in enterprises for answering the needs of prediction and optimization because of the emphasis on machine learning techniques. Furthermore, Hsinchun et al. (2012) clarify the development that in the literature the term business intelligence first appeared in the 1990s whereas business analytics first appeared in 2001 and gained popularity after 2007. The authors also point out that there is a huge contrast between the number of publications that the two terms related to. By 2012 the number of publications of business intelligence is more than 10 times of business analytics, and business analytics publications are growing at a fast pace, whereas the number of publications related to business intelligence stays stable.

Besides business analytics and business intelligence, there is another term that calls our attention: business intelligence and analytics. This term appeared in 4 papers, and the paper with the highest number of citations (Business intelligence and analytics: From big data to big impact), uses this term. The authors of the paper introduce business intelligence and analytics, a more inclusive term, to bridge the gap between business intelligence and business analytics. However, this term is not necessary. The birth of this term was in 2012 where the idea business analytics was not widely known nor developed; thus, this term was introduced to serve as a transition in the period. The main functionality of business intelligence is reporting historical data (Varshney \& Mojsilovic, 2011), and this functionality is covered in descriptive analytics (Gorman \& Klimberg, 2014), a subset of business analytics. 


\section{Applications}

During the review of the literature, we encountered a large of number applications of business analytics, and this proves that the usage of business analytics is comprehensive. These applications can be categorized into two parts: specific areas of a company and different industry sectors. The business areas we found are supply chain, finance and accounting, human resources. The industry sectors include e-services, retailing, politics, public security, healthcare, sports, and social welfare.

\subsection{Business Areas}

Oliveira et al. (2012) and Trkman, McCormack, De Oliveira and Ladeira (2010) both mention the Supply Chain Operations Reference (SCOR) model, and discuss the impact of business analytics in the four aspects of the model: Plan, Source, Make, and Deliver. Also, the investment of business analytics in the "Make" aspect of the supply chain can bring a huge improvement in the business process (Trkman et al., 2010). Furthermore, planning in supply chain management is about balancing the demand and productivity, and business analytics plays an important row in predicting customer demand and optimizing the selling price in this process (Chae \& Olson, 2013).

An example of the application of business analytics in supply chain management (also called supply chain analytics) is that for large manufacturers, they usually have a long list of suppliers to choose from, and in this case, business analytics is indispensable in selecting the most suitable suppliers based on a range of evaluation variables (Trkman et al., 2010). Chae and Olson (2013) define supply chain analytics as "IT-enabled, analytical dynamic capabilities for improving supply chain performance" (page 12). Supply chain analytics can yield powerful and productive supply chain in competitive business conditions (Chae \& Olson, 2013), also reduce cost and enhance client experience (Sahay \& Ranjan, 2008).

Business analytics can be helpful from different aspects of the scenario of accounting. Descriptive analytics is appropriate for financial reporting, which summarizes and presents the financial position of an enterprise (Appelbaum et al., 2017). Moreover, with the results provided by descriptive analytics, accountants can apply machine learning techniques to forecast organizational performance in the future, and this process can be seen as predictive analytics (Appelbaum et al., 2017). Finally, with the information acquired from the previous two processes, prescriptive can be employed to provide useful recommendations for future planning and decision making (Appelbaum et al., 2017). Business analytics is also crucial in processing financial time series to support decision making; specifically, Varshney and Mojsilovic (2011) propose two methods (logistic regression with risk factor constraints and inference of common signal structure) to process financial signals by deploying business analytics.

Business analytics applied in the human resources field (also called HR analytics or talent analytics) is still in the preliminary stage of application, and it is not used extensively yet (Pape, 2016). Another existing problem is that many companies did not collect sufficient human resource data for deploying HR analytics (Pape, 2016). Regarding the components, HR analytics is comprised of "the correlation between performance score and compensation, prediction of number of employees expected to leave the company, time to fill vacancies, employee count and estimated monetary value of performance difference in role" (Pape, 2016: page 692).

\subsection{Industry Sectors}

Hsinchun et al. (2012) consider that the second generation of business analytics is based on web and unstructured data. These unstructured web-based data, different from the traditional transactional data, which are usually structured, can help enterprises understand the opinions and purchase preferences of their customers (Hsinchun et al., 2012). Moreover, analyzing these customer data is also the foundation of a product recommender system, which is indispensable for today's e-commerce platforms (Hsinchun et al., 2012). Wagner, Brandt and Neumann (2016) provide us with a more specific example: car-sharing business, and the example shows us how business analytics empowers this emerging business sector and leverages its operational efficiency.

Business analytics can help the decision-making process and enhance business performance. It works the same for retailing business. The approach that deploys business analytics in the context of retailing business to obtain 
customer preference and shopping characteristics information can also be called retail business analytics or basket analytics (Griva, Bardaki, Pramatari \& Papakiriakopoulos, 2018). More specifically, applying data mining techniques on customer visit data can cluster customer segmentation (Griva et al., 2018), which helps make strategic product customization. Griva et al. (2018) present a real example of fast-moving consumer goods (FMCG) retailing, using the data of more than 300 points of sales in Greece from a European FMGC company.

In the most cited paper among the ones selected, Hsinchun et al. (2012) mention three areas of application (politics, healthcare, and public security) that are usually considered as non-business fields. Hence, it is significant to consider these areas and view business analytics from a broader perspective. As an example, Hsinchun et al. (2012) view politics 2.0 and e-government as an application of business analytics because these two fields use some techniques of business analytics such as social network analysis and opinion mining. Besides, in security and public safety, business analytics can support "criminal association rule mining and clustering; criminal network analysis; spatial-temporal analysis and visualization; multilingual text analytics; sentiment and affect analysis; cyberattacks analysis and attribution" (Hsinchun et al., 2012: page 1173). Also, many countries such as US, Japan, and Singapore have already adopted business analytics in the public security field, for example, employing business analytics to monitor and anticipate the happening of epidemics and famine (Calof et al., 2015). Enabled by sentiment analysis of web data, business analytics also works for policy-making, and it can be used to forecast and estimate the result of the implementation of policy (Calof et al., 2015).

The deployment of business analytics in healthcare can be done in three aspects: genomics data; electronic health records (EHRs); and social media data (Hsinchun et al., 2012). Especially for EHRs, this kind of electronic records systems have been adopted in hospitals worldwide, and these data are highly potential for improving healthcare quality (Hsinchun et al., 2012). The data source in healthcare includes data from pharmaceutical companies, insurance companies (insurance billing and claims), hospitals and clinics (such as electronic health records, laboratory results, and diagnostic images) (Ward, Marsolo \& Froehle, 2014). The employment of business analytics in healthcare faces three major challenges: difficulty of data extraction due to the barriers between health organizations, absence of national standard in healthcare data, shortage of capable analytical professionals in healthcare systems (Ward et al., 2014). To sum up, business analytics by assembling patient information can improve the allocation of medical resources, enhance efficient healthcare delivery, and support policy-making (Wang \& Byrd, 2017).

Troilo et al. (2016) name the use of business analytics in the sports industry as sport analytics, and in this context, business analytics is viewed as a tool to promote profits (Troilo et al., 2016). In the sports industry, analytics has already been deployed on leveraging players' performance, but using business analytics to improve operation and drive revenue remains as a novelty (Troilo et al., 2016). The authors designed a survey to test their hypotheses, and the hypotheses are proved that "managers do perceive that analytics increase revenues" and "the use of analytics will increase revenues" (Troilo et al., 2016: page 74). On the other side, we noticed a new field of application, social welfare. As an example, Hindle and Vidgen (2018) apply business analytics in the food bank sector, aimed at fighting against food poverty. The authors used analytical tools to visualize and locate the demand of food and predict the place of extra food banks needed.

\section{Education and Training in Business Analytics}

Enterprises are looking for professionals that "are able to understand business needs, interpret the analyses performed on big data and provide leadership for data-informed decision making in their organizations" (Chiang et al., 2012: page 12:3). It is important to understand the current education and training scenario.

There are two kinds of programs; one is offered by universities, the other by tech organizations. Regarding the first kind (university education), these programs are usually housed in business schools, but the participating departments do not only include information systems, marketing, and management sciences, but also fields such as computer science, statistics, mathematics, and industrial engineering (Sharda et al., 2013). Talking about the second kind of programs (training programs), they are usually provided by the companies. For example, tech giants such as IBM and Oracle offer certification courses targeted at training college student extracurricular skills needed by the market (Sharda et al., 2013). Furthermore, Hsinchun et al. (2012) comment that business analytics education is 
ideal to be developed in graduate level due to the prerequisite of knowledge, and there are three options of developing programs for business analytics training: initiating new master degrees in business analytics; adjusting the current master programs in information systems to create specialization in business analytics in these programs; and offering certificate programs designed for working professionals in IT or business, with online or on-site delivery (Hsinchun et al., 2012).

One characteristic of these business analytics programs is that they are usually located in business schools with the participation of data science and management information systems (Gorman \& Klimberg, 2014), and this differs business analytics programs from pure data science (DS) programs, which are more related to computer science and the manipulation of advanced algorithms (Chiang et al., 2012). From the point of view of Hsinchun et al. (2012), the education of business analytics is enabled by the integration of information systems (IS), computer science, statistics, and management science (Hsinchun et al., 2012). Especially for IS programs, for answering the needs of this new era of business analytics, housing IS programs in business schools provides students access to both information technologies and business domain knowledge (such as marketing, economics, finance, and human resources) (Hsinchun et al., 2012). Another feature is that the arrangement of the courses in business analytics education programs are heterogeneous, but the courses tend to be applied and practical in the workspace, at the same time, these courses focus more on the breadth of knowledge rather than on the depth, and the core of the courses is using analytical techniques to solve business problems (Gorman \& Klimberg, 2014).

The education in business analytics expects to foster professional with solid knowledge and skills in both technology and business, and they can transform structured and unstructured data into practical insights and finally apply them into business (Chiang et al., 2012). Therefore, the education of business analytics is born to be interdisciplinary, and this means business analytics program should not only involve analytical skills but also knowledge of business fields; additionally, communication skills are also indispensable (Hsinchun et al., 2012). Chiang et al. (2012) explain in details that the skills needed for business analytics professionals can be divided into three categories: analytical skills, which mainly include data mining and statistical analysis; information technology skills, which involve database management and handling data of large scale; and business knowledge in fields such as operations, marketing, logistics, finance, and accounting, as well as adequate communication skills (Chiang et al., 2012). Moreover, business analytics is practice-oriented; thus, it is important to combine hands-on projects and in-company internships with the curriculum (Hsinchun et al., 2012). Hence, it is essential to have a strong tie between academic programs and the industry (Hsinchun et al., 2012).

\section{Research Techniques}

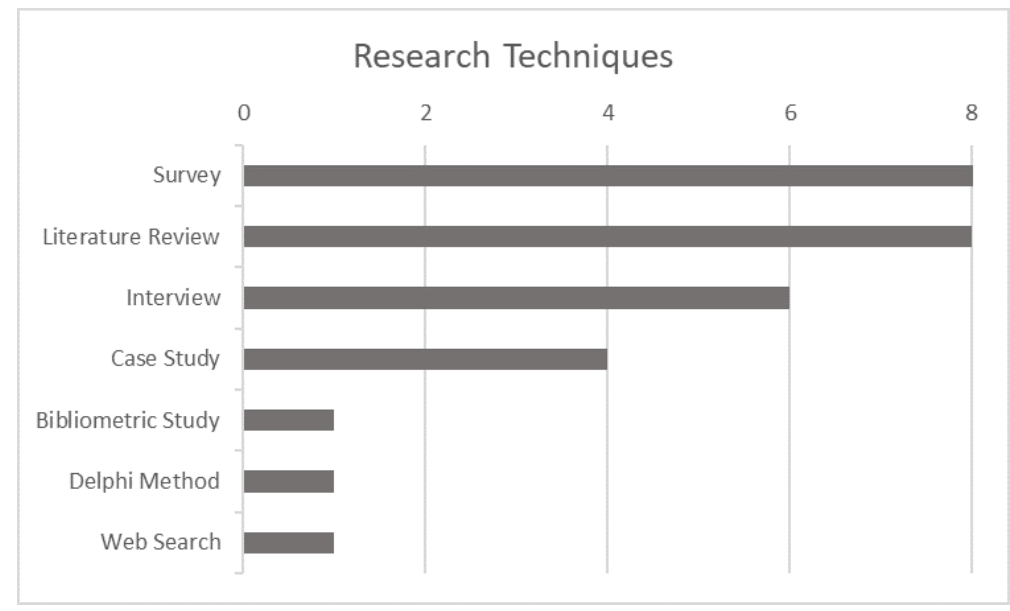

Figure 3. Research Techniques in the Literature Selected

The assessment of the research techniques serves as a valuable reference for future studies in designing research processes. Literature review is a common method in this field. What deserves attention is that there are five papers [(Bedeley, Ghoshal, Iyer \& Bhadury, 2018; Kowalczyk \& Buxmann, 2015; Pape, 2016; Phillips-Wren, Iyer, Kulkarni 
\& Ariyachandra, 2015; Troilo et al., 2016)] also included practitioners' literature in the review. Additionally, Hsinchun et al. (2012) conducted a bibliometric study and drew some useful conclusion that that publications related to business intelligence were more than ten times of business analytics, and "while the overall publication trend for business intelligence remained stable, business analytics and big data publications had seen a faster growth pattern in recent years" (Hsinchun et al., 2012: page 1179).

Survey is a popular research technique in social science. Nine papers used surveys in the study, and the surveys were distributed either through email or online questionnaires. An interesting finding is that the response rate drops quickly when the number of surveys distributed gets bigger. For example, (Cao, Duan \& Li, 2015) distributed 103,000 copies of survey, and the composite response rate was only $0.715 \%$. Whereas Klatt, Schlaefke and Moeller (2011) and Troilo et al. (2016) had a much smaller target, less than 300 in both cases, and the response rates were higher than $35 \%$. Undoubtedly, we also need to take into account that with different research purposes, the target size varies a lot. However, it is important to have a clear and precise scope in conducting a survey.

Case studies, interviews, Delphi method, and web search are the other four strategies encountered in the review for gathering knowledge. Compared with literature reviews, these methods are more flexible and agile. Moreover, data obtained from these techniques are closer to the industry. However, these approaches are not isolated, and a combination of techniques are used in a study at the same time.

Regarding case studies, Kowalczyk and Buxmann (2015) investigated 11 cases by collecting information from semi-structured interviews and surveys to investigate business intelligence and analytics support in the decisionmaking process, and the cases covered seven industries (telecommunication, media, finance, consumer, tourism, finance, and logistics). In the study of Shanks and Bekmamedova (2012), the case study took place in a large Australian financial services firm to investigate the customer analytics function. Bedeley et al. (2018) designed a case study of five participants from three companies of different industries (education, analytics consulting, and marketing and sales). Ultimately, Wixom et al. (2013) presented a case study of a fashion retailer to examine how to maximize value from business analytics. Among these four papers that use case study, the first three papers also conducted semi-structure interviews to acquire information.

The other two highlighted techniques are web search and Delphi study. Gorman and Klimberg (2014) intended to investigate the current business analytics academic programs, in this case, academic literature is not helpful since education in business analytics is a relatively new topic; thus, the authors conducted web searches and interviewed representatives of some business analytics programs. Web search is an effective method when there is no adequate information in the literature. On the other hand, Cosic, Shanks and Maynard (2015) employed Delphi method (also called Delphi study) to support the development of a business analytics capability framework. In the study of Cosic et al. (2015), 20 participants were invited from academia and industry, and there were three rounds in total to reach an agreement and come up with an acceptable result of the framework.

\section{Conclusions}

The research in business analytics is growing exponentially according to our analysis. Among different approaches of defining business analytics, many mentioned decision making, and it is closely related to the functionality of business analytics. Based on the functionality, a popular way to define business analytics is divide it into three kinds: descriptive analytics, predictive analytics, and prescriptive analytics. Furthermore, the three most popular research techniques were survey, literature review, and interview, whereas bibliometric study, Delphi method, and web search were less common and only appeared once. Finally, business analytics is interdisciplinary, and successful training should be a combination technical, analytical, and business skills. We think education and training in business analytics still has a long way to develop, and this topic deserves attention of future research.

\section{Declaration of Conflicting Interests}

The authors declared no potential conflicts of interest with respect to the research, authorship, and/or publication of this article. 


\section{Funding}

The authors received no financial support for the research, authorship, and/or publication of this article.

\section{References}

Appelbaum, D., Kogan, A., Vasarhelyi, M., \& Yan, Z. (2017). Impact of business analytics and enterprise systems on managerial accounting. International Journal of Accounting Information Systems, 25(March), 29-44. https://doi.org/10.1016/j.accinf.2017.03.003

Bedeley, R.T., Ghoshal, T., Iyer, L.S., \& Bhadury, J. (2018). Business Analytics and Organizational Value Chains: A Relational Mapping. Journal of Computer Information Systems, 58(2), 151-161. https://doi.org/10.1080/08874417.2016.1220238

Calof, J., Richards, G., \& Smith, J. (2015). Foresight, Competitive Intelligence and Business Analytics - Tools for Making Industrial Programmes More Efficient. Foresight-Russia, 9(1), 68-81. https://doi.org/10.17323/1995-459X.2015.1.68.81

Cao, G., Duan, Y., \& Li, G. (2015). Linking Business Analytics to Decision Making Effectiveness: A Path Model Analysis. IEEE Transactions on Engineering Management, 62(3), 384-395. https://doi.org/10.1109/TEM.2015.2441875

Chae, B. (2014). A complexity theory approach to IT-enabled services (IESs) and service innovation: Business analytics as an illustration of IES. Decision Support Systems, 57(1), 1-10. https://doi.org/10.1016/j.dss.2013.07.005

Chae, B.K., \& Olson, D.L. (2013). Business Analytics for Supply Chain: a Dynamic-Capabilities Framework. International Journal of Information Technology \& Decision Making, 12(01), 9-26. https://doi.org/10.1142/S0219622013500016

Chiang, R.H.L., Goes, P., \& Stohr, E.A. (2012). Business Intelligence and Analytics Education, and Program Development. ACM Transactions on Management Information Systems, 3(3), 1-13. https://doi.org/10.1145/2361256.2361257

Cosic, R., Shanks, G., \& Maynard, S.B. (2015). A business analytics capability framework. Australasian Journal of Information Systems, 19. https://doi.org/10.3127/ajis.v19i0.1150

Davenport, T H., \& Harris, J.G. (2007). Competing on Analytics: The New Science of Winning (1st ed.). Harvard Business School Press.

Duan, L., \& Xiong, Y. (2015). Big data analytics and business analytics. Journal of Management Analytics, 2(1), 1-21. https://doi.org/10.1080/23270012.2015.1020891

Fink, A. (2005). Conducting Research Literature Reviews: From the Internet to Pape. SAGE.

Gorman, M.F., \& Klimberg, R.K. (2014). Benchmarking Academic Programs in Business Analytics. Interfaces, 44(3), 329-341. https://doi.org/10.1287/inte.2014.0739

Griva, A., Bardaki, C., Pramatari, K., \& Papakiriakopoulos, D. (2018). Retail business analytics: Customer visit segmentation using market basket data. Expert Systems with Applications, 100, 1-16.

https://doi.org/10.1016/j.eswa.2018.01.029

Harzing, A., \& Alakangas, S. (2016). Google Scholar, Scopus and the Web of Science: a longitudinal and crossdisciplinary comparison. Scientometrics, 106(2), 787-804. https://doi.org/10.1007/s11192-015-1798-9

Hindle, G.A., \& Vidgen, R. (2018). Developing a business analytics methodology: A case study in the foodbank sector. European Journal of Operational Research, 268(3), 836-851. https://doi.org/10.1016/j.ejor.2017.06.031

Holsapple, C., Lee-Post, A., \& Pakath, R. (2014). A unified foundation for business analytics. Decision Support Systems, 64, 130-141. https://doi.org/10.1016/j.dss.2014.05.013

Hsinchun, C., Roger, H.L.C., \& Veda, C.S. (2012). Business Intelligence and Analytics: From Big Data To Big Impact. MIS Quarterly, 36(4), 1293-1327. https://doi.org/10.1016/S0140-6736(09)61833-X

Klatt, T., Schlaefke, M., \& Moeller, K. (2011). Integrating business analytics into strategic planning for better performance. Journal of Business Strategy, 32(6), 30-39. https://doi.org/10.1108/02756661111180113 
Kowalczyk, M., \& Buxmann, P. (2015). An ambidextrous perspective on business intelligence and analytics support in decision processes: Insights from a multiple case study. Decision Support Systems, 80, 1-13.

https://doi.org/10.1016/j.dss.2015.08.010

Larson, D., \& Chang, V. (2016). A review and future direction of agile, business intelligence, analytics and data science. International Journal of Information Management, 36(5), 700-710. https://doi.org/10.1016/j.ijinfomgt.2016.04.013

Okoli, C. (2015). A Guide to Conducting a Standalone Systematic To cite this version: A Guide to Conducting a Standalone Systematic Literature Review. Communications of the Association for Information Systems, 37, 879-910. https://doi.org/10.17705/1CAIS.03743

Oliveira, M.P.V. De, McCormack, K., \& Trkman, P. (2012). Business analytics in supply chains - The contingent effect of business process maturity. Expert Systems with Applications, 39(5), 5488-5498.

https://doi.org/10.1016/j.eswa.2011.11.073

Pape, T. (2016). Prioritising data items for business analytics: Framework and application to human resources. European Journal of Operational Research, 252(2), 687-698. https://doi.org/10.1016/j.ejor.2016.01.052

Phillips-Wren, G., Iyer, L. S., Kulkarni, U., \& Ariyachandra, T. (2015). Business Analytics in the Context of Big Data. Communications of the Association for Information Systems, 37(23), 448-472. https://doi.org/10.1109/MITP.2014.44

Sahay, B.S., \& Ranjan, J. (2008). Information Management \& Computer Security Article information: Information Management \& Computer Security, 16(1), 28-48. https://doi.org/10.1108/09685220910964027

Schläfke, M., Silvi, R., \& Möller, K. (2013). A framework for business analytics in performance management. International Journal of Productivity and Performance Management, 62(1), 110-122. https://doi.org/10.1108/17410401311285327

Shanks, G., \& Bekmamedova, N. (2012). Achieving benefits with business analytics systems: An evolutionary process perspective. Journal of Decision Systems, 21(3), 231-244. https://doi.org/10.1080/12460125.2012.729182

Sharda, R., Asamoah, D.A., \& Ponna, N. (2013). Research and pedagogy in business analytics: Opportunities and illustrative examples. Journal of Computing and Information Technology, 21(3), 171-183.

https://doi.org/10.2498/cit.1002194

Sharma, R., Mithas, S., \& Kankanhalli, A. (2014). Transforming decision-making processes: a research agenda for understanding the impact of business analytics on organisations. European Journal of Information Systems, 23(4), 433-441. https://doi.org/10.1057/ejis.2014.17

Shen, K.Y., \& Tzeng, G.H. (2016). Contextual Improvement Planning by Fuzzy-Rough Machine Learning: A Novel Bipolar Approach for Business Analytics. International Journal of Fuz:y Systems, 18(6), 940-955.

https://doi.org/10.1007/s40815-016-0215-8

Trkman, P., McCormack, K., De Oliveira, M.P.V., \& Ladeira, M.B. (2010). The impact of business analytics on supply chain performance. Decision Support Systems, 49(3), 318-327. https://doi.org/10.1016/j.dss.2010.03.007

Troilo, M., Bouchet, A., Urban, T.L., \& Sutton, W.A. (2016). Perception, reality, and the adoption of business analytics: Evidence from North American professional sport organizations. Omega (United Kingdom), 59, 72-83. https://doi.org/10.1016/j.omega.2015.05.011

Varshney, K.R., \& Mojsilovic, A. (2011). Business Analytics based on financial time series: Methodologies for using data to gain insight into business performance and drive business planning. IEEE Signal Processing Magazine, (September), 83-93. https://doi.org/10.1109/MSP.2011.941554

Wagner, S., Brandt, T., \& Neumann, D. (2016). In free float: Developing Business Analytics support for carsharing providers. Omega (United Kingdom), 59, 4-14. https://doi.org/10.1016/j.omega.2015.02.011

Wang, Y., \& Byrd, T.A. (2017). Business analytics-enabled decision-making effectiveness through knowledge absorptive capacity in health care. Journal of Knowledge Management, 21(3), 517-539. https://doi.org/10.1108/JKM-08-2015-0301

Ward, M.J., Marsolo, K. ., \& Froehle, C.M. (2014). Applications of business analytics in healthcare. Business Horizons, 57(5), 571-582. https://doi.org/10.1016/j.bushor.2014.06.003 
Wixom, B. H., Yen, B., \& Relich, M. (2013). Maximizing Value from Business Analytics. MIS Quarterly Executive, 12(2), 111-123. https://doi.org/10.1108/02635570910926564

Journal of Industrial Engineering and Management, 2020 (www.jiem.org)

\section{(c) $(1)(3$}

Article's contents are provided on an Attribution-Non Commercial 4.0 Creative commons International License. Readers are allowed to copy, distribute and communicate article's contents, provided the author's and Journal of Industrial Engineering and Management's names are included. It must not be used for commercial purposes. To see the complete license contents, please visit https://creativecommons.org/licenses/by-nc/4.0/. 